\title{
Anomalous left coronary artery arising from the pulmonary artery in hypoplastic left hearts: Case series and review of literature
}

\author{
Meena Nathan, MD, ${ }^{\mathrm{a}}$ Sitaram Emani, MD, ${ }^{\mathrm{a}}$ Gerald Marx, MD,${ }^{\mathrm{b}}$ and Frank Pigula, MD, ${ }^{\mathrm{a}}$ Boston, Mass
}

Anomalous left coronary artery arising from the pulmonary artery (ALCAPA) occurring in the setting of single ventricle disease is rare. Preoperative recognition of the lesion is critical for intraoperative cardiopulmonary bypass and surgical management. We present a 6-case series from Children's Hospital Boston with a review of literature.

\section{CLINICAL SUMMARY}

A retrospective review of 552 patients undergoing stage I palliation between 1995 and 2010 was performed. ALCAPA was identified in 6 patients.

Six cases of ALCAPA in hypoplastic left heart syndrome (HLHS) were found in this retrospective review (Table 1). In 5 patients, the diagnosis was made intraoperatively. In the first 4 patients, ALCAPA was identified late in the procedure (ie, after ductal ligation), and all 4 patients died of myocardial failure in the postoperative period. In the fifth patient, ALCAPA was identified during dissection of the right pulmonary artery (RPA). Care was taken to preserve coronary perfusion by snaring the branch pulmonary arteries and delaying ductal ligation. Cardioplegia was delivered to both coronary arteries via the ascending aorta and the controlled main pulmonary artery (MPA). This patient survived. In the sixth patient, diagnosis was made preoperatively by echocardiography and catheterization (Figures 1 and 2). Perfusion and cardioplegia were handled as described above, and this patient died of myocardial failure.

\section{DISCUSSION}

ALCAPA in the absence of significant congenital heart disease occurs in $0.25 \%$ to $0.5 \%$ of live births. ${ }^{1}$ The incidence when associated with complex congenital heart disease is unknown, especially as it pertains to HLHS. In our series, a preoperative diagnosis was made in only 1 patient. With the recent findings of this anomaly in HLHS, our center has become vigilant in defining the coronary arteries

\footnotetext{
From the Departments of Cardiac Surgery ${ }^{\mathrm{a}}$ and Cardiology, ${ }^{\mathrm{b}}$ Children's Hospital Boston, Harvard Medical School, Boston, Mass.

Received for publication Aug 13, 2010; accepted for publication Oct 17, 2010; available ahead of print Jan 19, 2011.

Address for reprints: Frank Pigula, MD, Department of Cardiac Surgery, Children's Hospital Boston, 300Longwood Ave, Bader 273, Boston, MA 02115 (E-mail: frank.pigula@cardio.chboston.org).

J Thorac Cardiovasc Surg 2011;142:225-7

$0022-5223 / \$ 36.00$

Copyright (C) 2011 by The American Association for Thoracic Surgery doi:10.1016/j.jtcvs.2010.10.031
}

before surgery. Obviously, this can be difficult to define with certainty by standard imaging modalities, such as echocardiography, catheterization, magnetic resonance imaging, or computed tomography scan. Thus, the true prevalence could be higher even as indicated in this retrospective review. Nonetheless, the presence of ALCAPA in patients with HLHS undergoing staged repairs will certainly affect medical and surgical management and ultimate prognosis.

Operative stage I palliation is the treatment of choice, and in the majority of cases ductal ligation is performed as the initial maneuver after initiation of cardiopulmonary bypass before dissection of posterior aspect of the MPA and branch pulmonary arteries (PAs). This can result in 1) coronary ischemia from a vascular steal from the anomalous coronary after ductal ligation and 2) accidental injury to anomalous coronary during dissection.

There have been several small case series documenting outcomes of this abnormality.

Saroli et $\mathrm{al}^{2}$ reported 4 patients with HLHS or Shone complex and coronary anomalies. Diagnosis was made intraoperatively in 2 of these patients, resulting in coronary injury, and they ultimately died. Diagnosis was made preoperatively in 2 of these patients (ALCAPA in 1, high origin of left coronary artery in 1), and they were successfully managed.

Nosal and colleagues ${ }^{3}$ describe a patient with HLHS in whom ALCAPA from the RPA was diagnosed intraoperatively because of left ventricular ischemia on initiation of cardiopulmonary bypass. Additional coronary perfusion was initiated with a second cannula in the MPA and snaring of distal branch PAs. Stage I palliation and reimplantation of ALCAPA were performed, and the patient was discharged on day 14 and subsequently underwent a successful bidirectional Glenn.

Bartram and colleagues, ${ }^{4}$ in their review of causes of death after the modified Norwood procedure, which involved 122 cases, reported only 1 case of accidental ligation of the left circumflex off RPA.

Daebritz and colleagues ${ }^{5}$ reviewed the outcomes of the stage I procedure at a single institution in the early phase of the procedure over a 9-year period. There were 131 cases of HLHS and 63 cases of NHLHS, with 26 deaths in the first 24 hours, of whom 15 had autopsy. Of interest, 10 were noted to have coronary ischemia. However, none of the 9 patients with HLHS had ALCAPA, whereas the single patient with NHLHS had an anomalous left circumflex from the PA. 
TABLE 1. Diagnosis, procedure, and outcomes

\begin{tabular}{|c|c|c|c|c|c|}
\hline Patient & Diagnosis & Procedure & ALCAPA diagnosis & ALCAPA management & Outcomes \\
\hline 1 & HLHS, AA/MA, PAPVR & $\begin{array}{c}\text { Stage I, BTS ligation of } \\
\text { anomalous coronary }\end{array}$ & $\begin{array}{l}\text { LCx from RPA on } \\
\text { transection of MPA }\end{array}$ & $\begin{array}{l}\text { Ligation 1-mm diameter } \\
\text { vessel with length } \\
\text { insufficient for } \\
\text { reimplantation }\end{array}$ & $\begin{array}{l}\text { Mortality } 1.5 \mathrm{~h} \\
\text { postoperatively }\end{array}$ \\
\hline 2 & $\begin{array}{l}\text { DORV, MA, sub-AS, } \\
\text { CoA, preoperative NEC }\end{array}$ & $\begin{array}{l}\text { Stage I, BTS ALCAPA } \\
\text { reimplantation }\end{array}$ & $\begin{array}{l}\text { LCx from RPA on } \\
\text { transection of MPA }\end{array}$ & $\begin{array}{l}\text { Reimplantation into } \\
\text { neoaortic root }\end{array}$ & Mortality $9 \mathrm{~h}$ postoperatively \\
\hline 3 & $\begin{array}{l}\text { HLHC, AS, MS, multiple } \\
\text { VSD }\end{array}$ & $\begin{array}{l}\text { Stage I, Sano, ALCAPA } \\
\text { reimplantation, } \\
\text { transitioned to ECMO }\end{array}$ & $\begin{array}{l}\text { LCx from LPA LV } \\
\text { ischemia on ductal } \\
\text { ligation }\end{array}$ & $\begin{array}{l}\text { Reimplantation into } \\
\text { neoaortic root }\end{array}$ & $\begin{array}{l}\text { Mortality POD } 13 \text { despite } \\
\text { ECMO support }\end{array}$ \\
\hline 4 & $\begin{array}{l}\text { DISRV, DORV, common } \\
\text { atrium, CoA, arch } \\
\text { hypoplasia, TAPVR }\end{array}$ & $\begin{array}{l}\text { Stage I, BTS, TAPVR } \\
\text { repair, ALCAPA } \\
\text { reimplantation transitioned } \\
\text { to ECMO }\end{array}$ & $\begin{array}{l}\text { LCA off RPA LV } \\
\text { ischemia on ductal } \\
\text { ligation }\end{array}$ & $\begin{array}{l}\text { Reimplantation into } \\
\text { neoaortic root }\end{array}$ & $\begin{array}{l}\text { Mortality POD } 21 \text { despite } \\
\text { ECMO support }\end{array}$ \\
\hline 5 & HLHC, MA, AS, VSD & $\begin{array}{l}\text { Stage I, BTS, ALCAPA } \\
\text { reimplantation }\end{array}$ & $\begin{array}{l}\text { LCA off RPA noted during } \\
\text { RPA dissection before } \\
\text { CPB }\end{array}$ & $\begin{array}{l}\text { Reimplantation into } \\
\text { neoaortic root }\end{array}$ & Survival to discharge \\
\hline 6 & $\begin{array}{l}\text { HLHC, dysplastic MV } \\
\text { with MS, AS, hypoplastic } \\
\text { LV, VSD, ALCAPA }\end{array}$ & $\begin{array}{l}\text { Stage I, BTS, MV repair, } \\
\text { ALCAPA reimplantation }\end{array}$ & $\begin{array}{l}\text { LCA off distal RPA close } \\
\text { to RUL branch take off, } \\
\text { diagnosed on preoperative } \\
\text { echocardiogram and } \\
\text { confirmed by } \\
\text { catheterization }\end{array}$ & $\begin{array}{r}\text { Reimplantation into } \\
\text { native aortic root }\end{array}$ & $\begin{array}{l}\text { Postoperative ECMO for } \\
\text { myocardial failure } \\
\text { LCA stenting, died of } \\
\text { fungal sepsis on POD } 43\end{array}$ \\
\hline
\end{tabular}

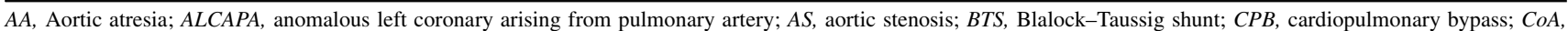
coarctation; $D I S R V$, double-inlet single right ventricle; $D O R V$, double-outlet right ventricle; $E C M O$, extracorporeal membrane oxygenation; $H L H C$, hypoplastic left heart complex; $H L H S$, hypoplastic left heart syndrome; $L C A$, left coronary artery; $L C x$, left circumflex; $L P A$, left pulmonary artery; $L V$, left ventricle; $L V D C C$, left ventricle-dependent coronary circulation; $M A$, mitral atresia; $M P A$, main pulmonary artery; $M S$, mitral stenosis; $N E C$, necrotizing enterocolitis; $P A P V R$, partial anomalous pulmonary venous return; $P O D$, postoperative day; $R P A$, right pulmonary artery; $R U L$, right upper lobe; $R V D C C$, right ventricle-dependent coronary circulation; $T A P V R$, total anomalous pulmonary venous return; $V S D$, ventricular septal defect.

On the basis of our clinical experience, preoperative identification of the coronary artery anatomy is essential. This might necessitate a combination of imaging strategies, including echocardiography, catheterization, magnetic resonance imaging, and computed tomography

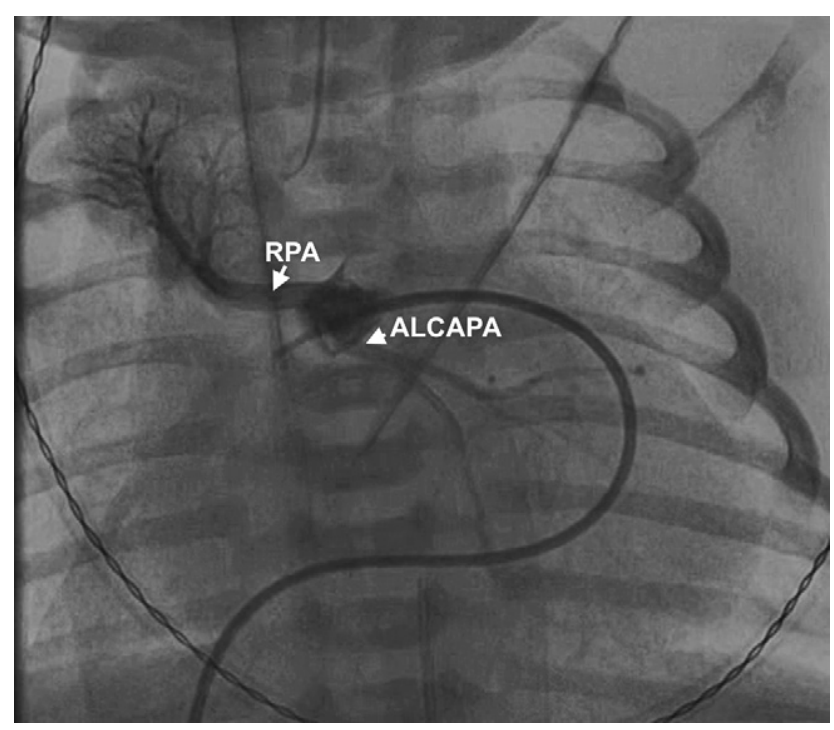

FIGURE 1. Anteroposterior view of ALCAPA arising from the RPA. $R P A$, Right pulmonary artery; $A L C A P A$, anomalous left coronary arising from pulmonary artery. angiography. Careful surgical examination of coronary anatomy before initiation of cardiopulmonary bypass remains key.

With the diagnosis established, management of cardiopulmonary bypass can be modified to include the following:

- maintenance of ductal patency with snaring of distal branch PAs to avoid coronary steal and myocardial ischemia;

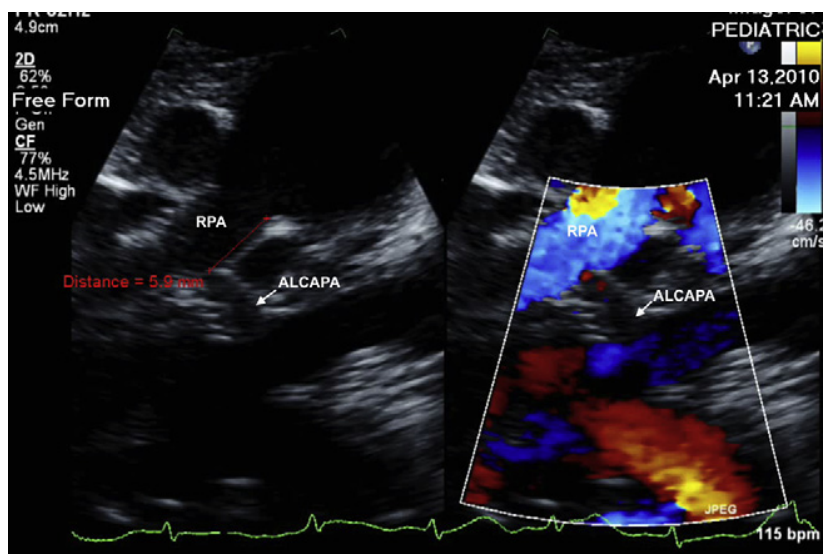

FIGURE 2. Echocardiographic images of left coronary artery arising from the RPA, $6 \mathrm{~mm}$ distal to the pulmonary arterial bifurcation. $R P A$, Right pulmonary artery; $A L C A P A$, anomalous left coronary arising from pulmonary artery. 
- cardioplegia administered simultaneously into the ascending aorta and isolated MPA/proximal branch PA; and

- reimplantation of ALCAPA with generous buttons to avoid distortion.

Alternative options would be a hybrid approach with PA banding distal to ALCAPA and reimplantation at time of comprehensive stage II, or neonatal transplantation.

\section{CONCLUSIONS}

The preoperative diagnosis of this rare entity is key because it allows for adequate surgical planning.

\section{References}

1. Dodge-Khatami A, Mavroudis C, Backer C. Anomalous origin of left coronary from pulmonary artery: collective review of surgical therapy. Ann Thorac Surg. 2002;74:946-55.

2. Saroli T, Gelehrter S, Gomez-Fifer CA, van der Velde ME, Bove EL, Ensing GJ. Anomalies of left coronary artery origin affecting surgical repair of hypoplastic left heart syndrome and Shone complex. Echocardiography. 2008;25:727-31. Epub 2008 Apr 27

3. Nosal M, Omeje IC, Poruban R. Hypoplastic left heartsyndrome with anomalous origin of left coronary artery from the right pulmonary artery: successful surgical treatment in a neonate. Eur J Cardiothorac Surg. 2005;28:497-8.

4. Bartram U, Grunenfelder J, Van Praagh R. Causes of death after the modified Norwood Procedure: a study of 122 postmortem cases. Ann Thorac Surg. 1997;64: 1795-802.

5. Daebritz SH, Nollert GD, Zurakowski D, Khalil PN, Lang P, del Nido PJ, et al. Results of Norwood stage I operation: comparison of hypoplastic left heart syndrome with other malformations. J Thorac Cardiovasc Surg. 2000; 119:358-67.

\title{
Percutaneous mitral valve repair as a bail-out strategy for patients with severe mitral regurgitation after cardiac surgery
}

\author{
Olaf Franzen, MD, ${ }^{\mathrm{a}}$ Moritz Seiffert, MD, ${ }^{\mathrm{b}}$ Stephan Baldus, MD, ${ }^{\mathrm{a}}$ Lenard Conradi, MD, ${ }^{\mathrm{b}}$ \\ Johannes Schirmer, MD, ${ }^{\mathrm{b}}$ Mathias Kubik, MD, ${ }^{\mathrm{b}}$ Thomas Meinertz, MD, ${ }^{\mathrm{a}}$ \\ Hermann Reichenspurner, MD, PhD, ${ }^{\mathrm{b}}$ and Hendrik Treede, MD, ${ }^{\mathrm{b}}$ Hamburg, Germany
}

With excellent long-term results, surgical valve repair is the standard treatment in patients with mitral valve (MV) disease, replacement being an option if reconstruction is not feasible. ${ }^{1,2}$ In patients with prohibitive operative risk, the MitraClip system (Abbott Laboratories, Abbott Park, Ill) has accomplished promising preliminary results reducing mitral regurgitation (MR). ${ }^{3,4}$ We performed this procedure as a bail-out approach in high-risk patients with severe MR not responding to intense medical therapy in the early postoperative period after cardiac surgery.

\section{CLINICAL SUMMARY}

From March to October 2009, 3 patients underwent coronary artery bypass grafting, tricuspid valve replacement, or

\footnotetext{
From the Departments of General and Interventional Cardiology, ${ }^{\mathrm{a}}$ and Cardiovascular Surgery, ${ }^{\text {b }}$ University Heart Center Hamburg, Germany.

Disclosures: Dr Franzen received funding for proctoring from E-Valve Inc, Menlo Park, California, and Abbott Laboratories, Abbott Park, Illinois.

Drs Franzen and Seiffert contributed equally to this work.

Received for publication May 18, 2010; accepted for publication Oct 23, 2010; available ahead of print Jan 19, 2011.

Address for reprints: Moritz Seiffert, MD, Department of Cardiovascular Surgery, University Heart Center Hamburg, Martinistrasse 52, 20246 Hamburg, Germany

(E-mail: m.seiffert@uke.de).

J Thorac Cardiovasc Surg 2011;142:227-30

$0022-5223 / \$ 36.00$

Copyright (C) 2011 by The American Association for Thoracic Surgery doi: $10.1016 /$ j.jtcvs. 2010.10 .037
}

aortic valve replacement combined with tricuspid valve repair at the University Heart Center Hamburg (Table 1). Preoperatively, mild to moderate MR was noted. Postoperatively, severe functional MR impeded hemodynamic stabilization necessitating prolonged inotropic support. To avoid early redo surgery associated with disproportional operative risk, an interventional approach was chosen after interdisciplinary discussion.

Percutaneous MV repair was performed with the MitraClip device, a polyester-covered metal clip, as previously described. ${ }^{5}$ Briefly, after introduction through the femoral vein and transseptal puncture, the steerable device was advanced across the MV. The clip was then positioned, and the leaflets were captured at the origin of the regurgitant jet creating a double-orifice simulating Alfieri's technique. Clip implantation was performed under fluoroscopic and transesophageal echocardiographic guidance (Figure 1). Follow-up echocardiographic evaluation was performed at discharge and 3 months after the procedure.

\section{RESULTS}

All 3 female patients (age, 71-78 years) were considered high-risk surgical candidates as predicted by standard risk-stratification tools (Table 1). Percutaneous MV repair was performed 5 to 7 days after primary surgery. Two clips were used in 2 of the patients, creating a triple-orifice area. MR was reduced from grade III-IV to I-II allowing for hemodynamic recompensation. There were no signs of mitral stenosis after clip implantation. 